\title{
Determination of parameters of abnormal wear of brake pads of freight cars
}

\author{
Vasyl Ravlyuk ${ }^{1, *}$, İsrail Elyazov ${ }^{2}$, Ihor Afanasenko ${ }^{1}$, and Mykola Ravliuk $^{1}$ \\ ${ }^{1}$ Ukrainian State University of Railway Transport, Department of Cars, 7 Feuerbach Sq., Kharkov, 61050, Ukraine \\ ${ }^{2}$ Azerbaijan Technical University, Department of Railway Transport Operation, 25 H. Javid Avy., Baku, Az 1073, Azerbaijan
}

\begin{abstract}
The complex of operational studies and theoretical research was performed on the occurrence of harmful wear that changes geometrical parameters of the useful contact area of the brake pads of freight cars at various established standard clearance between the pad and the wheel, which significantly impairs the braking efficiency of trains. The inspections of the mechanical part of the brakes attracted attention to the abnormal wear of the brake pads of the freight cars, which occurs because the common centre of gravity of the pad and the brake shoe, which are on the pendular suspension, do not coincide with the centre of the hole in the brake strut for any pad. The results of calculations using the coordinate method performed in the Mathcad software environment and the graphical one performed in AutoCAD to determine the geometrical parameters of the formation of the upper harmful wear of the pad depending on the standard clearance between the wheel and the brake pad were compared to proved theoretically that the error between them does not exceed 5-7\%.
\end{abstract}

\section{Introduction}

As the speed of movement and axial loads during transportation of goods at Ukrzaliznytsya JSC have been increasing, as well as the periods between repairs of the brake system of freight cars should be extended, a number of new design solutions have been applied to ensure the normal wear of brake pads. However, some of the proposed solutions have proven to be ineffective, so the issue of abnormal wear of brake pad remains in abeyance [1].

To scientifically substantiate the innovations that ensure the prolongation of the safe operation of the brake pads, we have summarized the material of a few studies which search for the ways to slow down the wear of brake pads of freight cars in Ukrzaliznytsia JSC.

\section{Analysis of the latest achievements}

Multiple studies have been devoted to the investigation of causes and effects of this negative phenomenon. In particular, [2] describes a device used in the brake rigging (BR) of bogies to retract the pads with automatic adjustment of their relative position with respect to the rolling surfaces of the wheels. However, it is important to note that such a device complicates the BR design of the bogie and requires systematic labour-intensive adjustments during the operation, hence, using it is impractical.

In [3], the stresses occurring in the brake pad were analyzed, the thermal analysis was performed using the SolidWorks software and an alternative solution life was suggested to improve the brake pad material and prolong the service life.

The authors in article [4] refer to various friction brake systems used in mechanical braking. It is noted that friction brake systems in which brake pads are used have adverse effect on the rolling surface of the wheels, as high temperatures occur in the "pad-wheel" friction zone, so disc brakes are preferred.

Foreign researchers are focused on the study of disc brakes, strength calculations of their elements, real-time observations of their operation, and also on the calculations of the temperature conditions of some elements of the brake systems of rolling stock $[5,6]$. When a train is braked with friction brakes, thermal energy is generated in the contact area of tribotechnical bodies, which is dissipated by forced convection, conduction, and radiation from the open surfaces of the brake.

Papers $[7,8]$ state that overheating of tribotechnical pairs can cause malfunction of the brake system and compromise the safety of movement. Therefore, considerable theoretical work is being done considering the elevation of temperature during braking for different speeds of movement and brake disc design.

Considering the analyzed literature sources, it should be noted that the problems of abnormal wear of the brake pads used in the brake systems of three-element bogies have not received sufficient attention yet.

\section{Purpose and tasks of the study}

The purpose of this study is determining the geometrical

\footnotetext{
* Corresponding author: ravvg@ukr.net
} 
parameters of the brake pads of freight cars in case of harmful wear.

To achieve the stated purpose, the following tasks must be solved:

- performing analysis of the causes of the upper harmful wear which changes geometrical parameters of the useful contact area of the brake pads and occurs during train movement in traction and run modes;

- developing a methodology for determining the geometrical parameters of the upper harmful wear of the pad depending on the standard clearance between the wheel and the brake pad to improve the braking efficiency of trains;

- plotting graphical dependencies according to the developed methodology: lengths of harmful wear of the brake pad on its horizontal wear; harmful area and the amount of wear of the pad on the amount of uneven wear depending on the clearance between the wheel and the pad to determine the geometrical parameters of the useful contact area of the pad;

- proposing techniques to eliminate the upper harmful attrition which causes abnormal wear of the brake pads during the movement of freight cars and significantly impairs the braking efficiency of trains.

\section{Results and discussion}

The results of inspections of the mechanical part of the brakes in the bogies of freight car demonstrated that some brake pads which had abnormal wear had been reinstalled in the car and already turned so that the harmful wear was at the bottom and the upper parts of the pads were intact. It should be noted that in accordance with the requirements of current regulatory and technological documents, turning brake pads is not recommended [9].

However, some workers in maintenance depot turn brake pads that were removed during the current repair or overhaul of the cars, claiming that this would equalize their wear and tear. The reason for it is the fact that the number of new pads is insufficient to replace the faulty pads in operation and the workers have to use the brake pads previously removed from the cars during the repairs turning them by $180^{\circ}$ (Fig. 1) for the subsequent operation of the freight cars.

Such actions are the reason why braking efficiency significantly deteriorates in the freight trains and multiple malfunctions of rolling surfaces of wheel pairs occur during the operation of such brake pads, which damage the railway infrastructure [10, 11].

Therefore, it should be noted that a violation of the instructions can lead to grave consequences on the railway, such as smash-ups, traffic accidents, and mishaps, etc., which is a direct threat to the safety of railway traffic. For this reason, conditions and devices should be developed to ensure that the brake pads in the bogies of freight cars are worn out evenly. As a consequence, first, they can be used within the entire period between depot repairs; second, the railway companies will save tens of thousands of hryvnias for the procurement of pads; and third, brake pads will be disposed of with only insignificant amount of the remaining working composite mass [12].
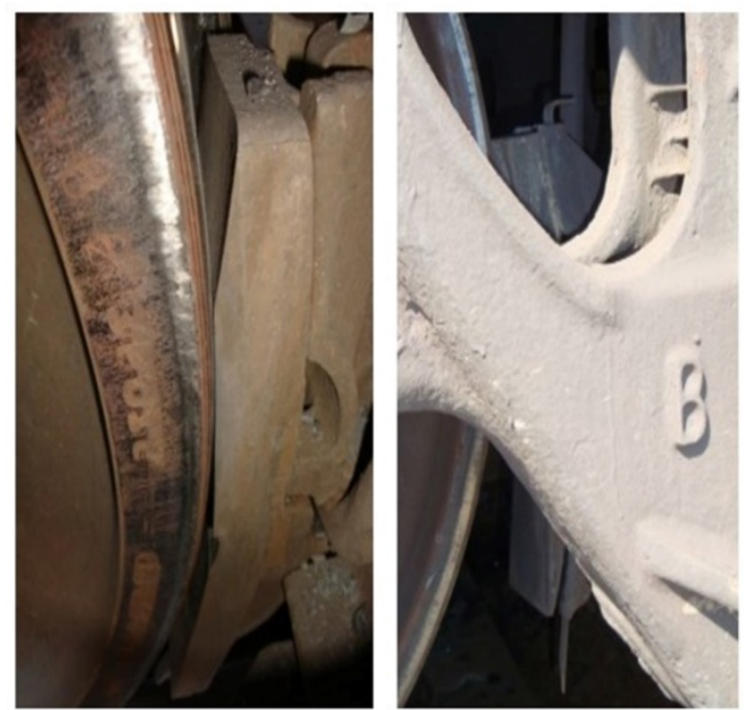

Fig. 1. View of a dual wedge-worn brake pad in operation.

Naturally, when the car is braked during the movement, friction occurs between the rolling surface of the wheel and the working surface of the brake pad causing friction wear. However, during the inspections of 16,640 pads in the freight cars of the operated fleet in maintenance depots, it was found that most of the pads are bent when the brake is released, their upper edges touch the rolling surface of the wheels and make friction during the movement. When the length of the harmful wear of the pad that reduces the useful area and affects the braking process was measured, it was found that it can take up to $150 \mathrm{~mm}$ of the total length of the pad (Fig. 2, a).

It should also be noted that two wear surfaces are formed on the pads: the upper one is where the pad is worn obliquely symmetrically as cars move without braking, quite intensively depending on the speed of movement; and the lower one which is used to brake the car.

In bogie BR of freight cars, the point of connection of the vertical levers with the brake strut is shifted towards the wheel relative to the points of connection of the triangle shoe with the pendulum suspension. This causes touching by the upper part of the pad of the wheel rim when the brakes are released (Fig. 2, b). As a result, a significantly thick wear of the top of the pad occurs, and consequently, the length of its working surface is reduced.

Studies have shown that the smaller the retraction distance of the pad from the wheel and the angle between the surface of the wheel rim and the working part of the pad is, the greater the length is which begins from the upper end of the pad and is subjected to wear when the brake is released.

However, it should be noted that, if a clearance is excessive, it is generally larger at the bottom of the pad (Fig. 2, c) than at the top, intensive wear occurs at the upper edge of the pad. 

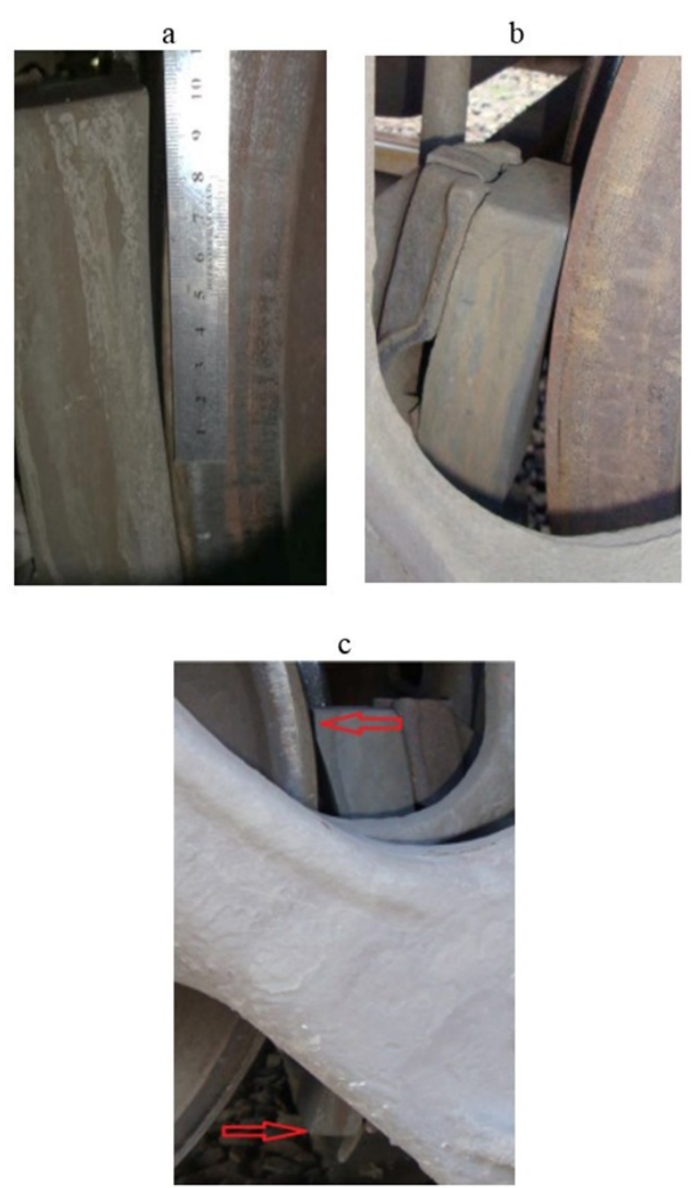

Fig. 2. Pictures of the wedge dual wear of the brake pad in operation: a - measurement of the length of harmful wear; $\mathrm{b}$ - interaction of the upper end with the rolling surface of the wheel during movement of the car; $\mathrm{c}$ - abnormal clearance between the pad and the wheel.

\subsection{Determination of geometrical parameters of the length of the harmful wear at the top of the brake pad with known wear at the top}

Design diagram of rotation of the brake pad with a shoe is shown in Fig. 3.

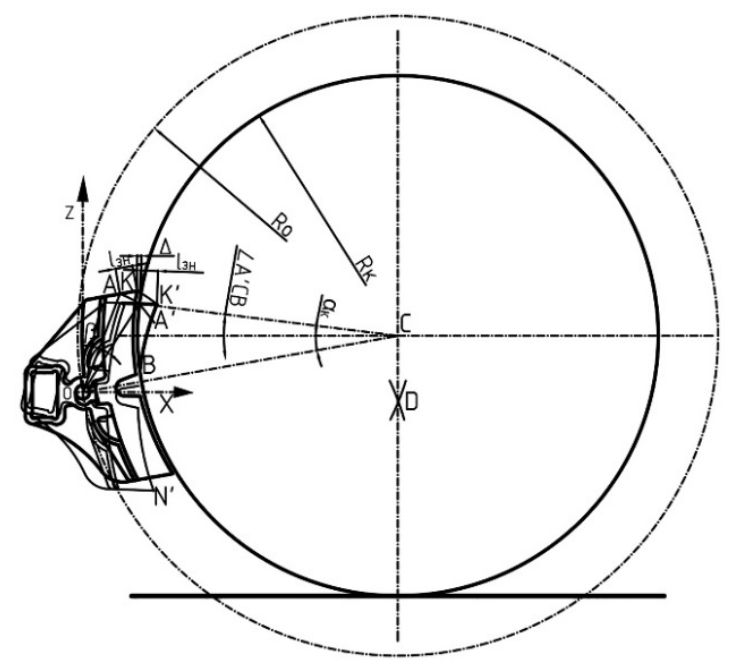

Fig. 3. Design diagram of rotation of the shoe with the pad.
The task is reduced to determination of the length of arc $\cup A^{\prime} B$, which can be calculated according to the following formula [13]

$$
\cup A^{\prime} B=\frac{\pi R \cdot \angle A^{\prime} C B}{180},
$$

where $R$ is the estimated radius of the car wheel, $\mathrm{m}$.

Let us denote the coordinate system at point $O$. Axis $Z$ is selected as vertical, and axis $X$ is selected as horizontal, as it is customary in car designing.

Calculations are performed using the coordinate method. First, the coordinates of point $A^{\prime}$ are calculated that is the point of intersection of the circle with the centre at point $O$ and radius $O A=O A^{\prime}$ and circles with the centre at point $C$ and radius $R$.

The equation for the circle with the centre at point $O$ and radius $O A$ will be as follows

$$
x^{2}+z^{2}=O A^{2},
$$

Relative to the circle with the centre in point $C$

$$
\left(x-x_{C}\right)^{2}+\left(z-z_{C}\right)^{2}=R^{2} \text {, }
$$

where $x_{C}, z_{C}$ are coordinates of point $C$. The position of point $C$ can be written as $x_{C}=R_{O} \cos \alpha, z_{C}=R_{O} \sin \alpha$, then equation (3) will be as follows

$$
\left(x-R_{O} \cos \alpha\right)^{2}+\left(z-R_{O} \sin \alpha\right)^{2}=R^{2} .
$$

where $R_{O}$ is the distance between points $O$ and $C ; \alpha$ is the angle of the pad relative to the centre of the wheel of the car.

The position of point $A^{\prime}$ is determined using the equation system

$$
\left\{\begin{array}{c}
x^{2}+z^{2}=O A^{2}, \\
\left(x-R_{O} \cos \alpha\right)^{2}+\left(z-R_{O} \sin \alpha\right)^{2}=R^{2},
\end{array}\right.
$$

it should be noted that the coordinates of point $A^{\prime}$ $x_{A^{\prime}}, Z_{A^{\prime}}>0$, in the selected coordinate system.

To determine the coordinates of points $A, K, K^{\prime}, N^{\prime}$ the diagram of rotation of the shoe with the pad is considered in details.

The diagram of rotation of the shoe with the pad relative to the pendulum suspension is shown in Fig. 4.

Position of points $A, K$ are related to the initial parameters of the "pendulum suspension - shoe - brake pad" system, initial pad thickness, wear value $l$, shoe size, wear of the pendulum suspension in the contact area with the shoe and the side frame of the bogie. To solve the problem, it was assumed that the shoe and brake shoe have standard sizes.

Angle $\beta$ is defined as the angle between two vectors $O A$ and $O A^{\prime}$, which is the angle of rotation of the pad relative to point $O$ 


$$
\beta=\arccos \left(\frac{x_{A} \cdot x_{A^{\prime}}+z_{A} \cdot z_{A^{\prime}}}{\sqrt{\left(x_{A}^{2}+z_{A}^{2}\right)} \sqrt{\left(x_{A^{\prime}}^{2}+z_{A^{\prime}}^{2}\right)}}\right) .
$$

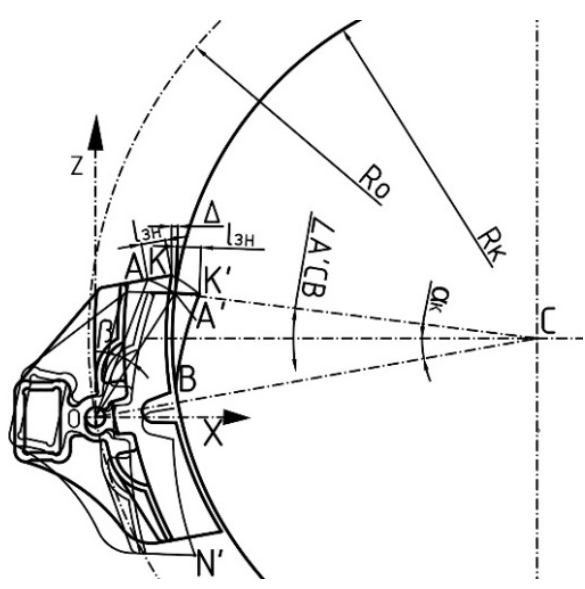

Fig. 4. Theoretical diagram of rotation of the shoe with the pad relative to the pendulum suspension.

Coordinates of points $K^{\prime}, N^{\prime}$ are determined from the known angle $\beta$ and initial points $K, N$.

To find the position of point $D$, circles with radius $R+\Delta$ are drawn from points $K^{\prime}, N^{\prime}$ (where $\Delta$ is the clearance between the pad and the wheel in the free state without turning the shoe with the pad) and their point of intersection is found which is point $D$

$$
\left\{\begin{array}{l}
\left(x-x_{K^{\prime}}\right)^{2}+\left(z-z_{K^{\prime}}\right)^{2}=(R+\Delta)^{2}, \\
\left(x-x_{N^{\prime}}\right)^{2}+\left(z-z_{N^{\prime}}\right)^{2}=(R+\Delta)^{2} .
\end{array}\right.
$$

Coordinates of point $B$ can be found as the intersection point of the circle with the centre at point $C$ circle radius $R$ and in point $D$ with the radius $R+\Delta$. An equation system is composed to determine those

$$
\left\{\begin{array}{c}
\left(x-R_{O} \cos \alpha\right)^{2}+\left(z-R_{O} \sin \alpha\right)^{2}=R^{2}, \\
\left(x-x_{D}\right)^{2}+\left(z-z_{D}\right)^{2}=(R+\Delta)^{2} .
\end{array}\right.
$$

Once the coordinates of points $A^{\prime}$ and $B$ are found, angle $\angle A^{\prime} C B$ can be found as an angle between two right lines $C A^{\prime}$ and $C B$.

Let us denote

$$
\begin{gathered}
U=\left(z_{C}-z_{A^{\prime}}\right)\left(z_{C}-z_{B}\right)+\left(x_{A^{\prime}}-x_{C}\right)\left(x_{B}-x_{C}\right), \\
V=\left(z_{C}-z_{A^{\prime}}\right)^{2}+\left(x_{A^{\prime}}-x_{C}\right)^{2}, \\
L=\left(z_{C}-z_{B}\right)^{2}+\left(x_{B}-x_{C}\right)^{2}, \\
\cos \angle A^{\prime} C B=\frac{|V|}{\sqrt{U \cdot L^{\prime}}}
\end{gathered}
$$

hence

$$
\angle A^{\prime} C B=\arccos \left(\frac{|V|}{\sqrt{U \cdot L}}\right) \text {. }
$$

Knowing the angle $\angle A^{\prime} C B$ the length of the arc is determined using the formula (1).

All the above equations were solved using Mathcad software [14]. Capabilities of the graphics software complex AutoCAD were used to compare the results of the calculation of the obtained data. The results of the calculation in AutoCAD of the dependence of the lengths of harmful wear of the brake pad on its known horizontal wear at the top and the clearances between the pad and the wheel are summarized in Table 1, while an example of graphical determination is shown in Fig. 5.

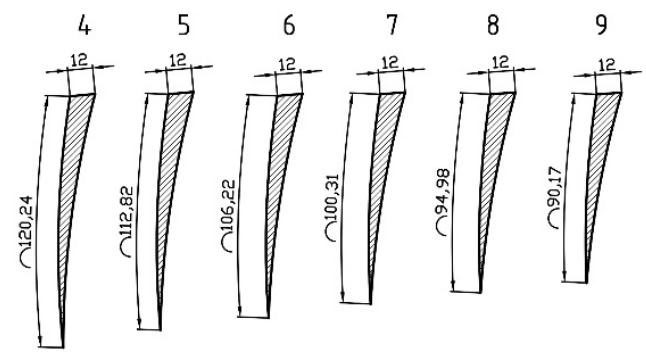

\begin{tabular}{|c|c|c|c|c|c|c|c|c|c|c|c|c|c|c|}
\hline & \multicolumn{14}{|c|}{ Known value of horizontal wear of the brake pad, $l, \mathrm{~mm}$} \\
\hline & -1 & $N$ & $n$ & $\nabla$ & in & 0 & $r$ & $\infty$ & $a$ & 은 & $=$ & $\simeq$ & $\cong$ & \pm \\
\hline & \multicolumn{14}{|c|}{ Defined length of a harmful wear of the brake pad, mm } \\
\hline & 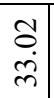 & $\begin{array}{l}\infty \\
0 \\
\dot{+} \\
n\end{array}$ & 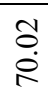 & 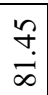 & $\begin{array}{l}\text { ஸे } \\
\stackrel{2}{8} \\
\stackrel{2}{2}\end{array}$ & $\frac{n}{a}$ & 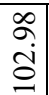 & $\begin{array}{l}\infty \\
0 \\
\hat{0} \\
0\end{array}$ & $\begin{array}{l}\vec{\sigma} \\
\stackrel{\Xi}{\Xi}\end{array}$ & $\begin{array}{l}\varrho \\
\dot{ \pm} \\
=\end{array}$ & $\begin{array}{l}\stackrel{9}{2} \\
\stackrel{2}{\Xi}\end{array}$ & $\begin{array}{l}\stackrel{さ}{\mathrm{~d}} \\
\stackrel{\mathrm{d}}{\mathrm{d}}\end{array}$ & $\begin{array}{l}\tilde{N} \\
\mathfrak{N} \\
\end{array}$ & 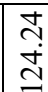 \\
\hline & $\begin{array}{l}\stackrel{ \pm}{\Delta} \\
\stackrel{\sim}{N}\end{array}$ & 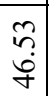 & $\begin{array}{l}\alpha \\
\delta \\
\delta\end{array}$ & $\begin{array}{l}n \\
i \\
i\end{array}$ & $\stackrel{0}{\infty}$ & $\begin{array}{l}\vec{\sim} \\
\infty \\
\infty \\
\infty\end{array}$ & $\begin{array}{l}2 \\
\dot{+} \\
\dot{\alpha}\end{array}$ & $\begin{array}{l}2 \\
0 \\
2\end{array}$ & 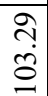 & 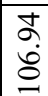 & $\begin{array}{l}\infty \\
0 \\
0 \\
0 \\
=\end{array}$ & $\begin{array}{l}\mathfrak{I} \\
\infty \\
\beth \\
\Xi\end{array}$ & $\begin{array}{l}\tilde{n} \\
\stackrel{n}{a} \\
=\end{array}$ & 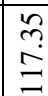 \\
\hline & $\begin{array}{l}0 \\
\cdots \\
\ddot{n}\end{array}$ & $\begin{array}{l}\stackrel{f}{f} \\
\dot{q}\end{array}$ & $\begin{array}{l}\infty \\
\infty \\
\dot{n} \\
i\end{array}$ & $\begin{array}{l}n \\
\tilde{b}\end{array}$ & $\stackrel{\ddot{n}}{\stackrel{r}{r}}$ & $\begin{array}{l}\stackrel{+}{+} \\
\stackrel{\infty}{\infty}\end{array}$ & $\begin{array}{l}\stackrel{q}{+} \\
\dot{\infty}\end{array}$ & $\begin{array}{l}\vec{b} \\
\dot{a}\end{array}$ & $\begin{array}{l}5 \\
0 \\
0\end{array}$ & $\begin{array}{l}\alpha \\
\alpha \\
\alpha\end{array}$ & ஸֶ & $\begin{array}{l}\tilde{1} \\
\stackrel{8}{0}\end{array}$ & $\begin{array}{c}\tilde{\infty} \\
\infty \\
0 \\
0\end{array}$ & $\stackrel{n}{\Xi}$ \\
\hline & 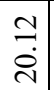 & $\begin{array}{l}n \\
i n \\
m\end{array}$ & \begin{tabular}{l}
\multirow{N}{*}{} \\
$\stackrel{\infty}{+}$
\end{tabular} & $\begin{array}{l}2 \\
m \\
\infty \\
\infty\end{array}$ & $\begin{array}{l}+ \\
\infty \\
0 \\
0\end{array}$ & 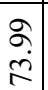 & $\begin{array}{l}8 \\
\stackrel{0}{ } \\
\infty\end{array}$ & $\begin{array}{l}\tilde{N} \\
\ddot{\infty}\end{array}$ & $\begin{array}{l}n \\
\stackrel{n}{a}\end{array}$ & $\stackrel{n}{r}$ & $\frac{\vec{N}}{\hat{a}}$ & $\begin{array}{l}\vec{n} \\
8 \\
0\end{array}$ & $\begin{array}{c}0 \\
0 \\
\dot{o} \\
0\end{array}$ & $\begin{array}{l}n \\
n \\
\tilde{c}\end{array}$ \\
\hline & $\begin{array}{l}\infty \\
\stackrel{1}{\check{c}}\end{array}$ & $\begin{array}{l}\stackrel{8}{ } \\
\dot{m} \\
m\end{array}$ & $\begin{array}{l}\mathcal{V} \\
\dot{\gamma} \\
\dot{\gamma}\end{array}$ & $\begin{array}{l}\text { กิ } \\
\hat{n}\end{array}$ & $\frac{\dddot{m}}{\vec{\sigma}}$ & $\begin{array}{l}\stackrel{m}{+} \\
\dot{0} \\
\dot{0}\end{array}$ & 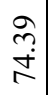 & $\begin{array}{l}\stackrel{8}{0} \\
\stackrel{2}{1}\end{array}$ & $\stackrel{\square}{\underset{\infty}{ \pm}}$ & $\begin{array}{l}\underset{1}{N} \\
\infty \\
\infty\end{array}$ & $\frac{a}{2}$ & \begin{tabular}{l}
$\infty$ \\
\multirow{a}{+}{} \\
$\dot{a}$
\end{tabular} & $\begin{array}{l}n \\
\infty \\
\hat{a} \\
\end{array}$ & $\stackrel{9}{\stackrel{8}{8}}$ \\
\hline & $\begin{array}{l}\vec{a} \\
\dot{n}\end{array}$ & $\begin{array}{l}\tilde{\alpha} \\
\infty \\
\sim\end{array}$ & $\begin{array}{l}\vec{\infty} \\
\dot{m}\end{array}$ & \begin{tabular}{l}
$\infty$ \\
\multirow{2}{0}{} \\
$\infty$ \\
$\dot{0}$
\end{tabular} & $\begin{array}{l}\vec{\infty} \\
\dot{0} \\
i\end{array}$ & 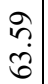 & $\begin{array}{l}\text { f. } \\
\text { gे }\end{array}$ & $\begin{array}{l}n \\
\dot{T} \\
\sim\end{array}$ & તุ. & 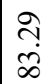 & $\begin{array}{l}\bar{\alpha} \\
\dot{0}\end{array}$ & $\frac{1}{\dot{a}}$ & $\begin{array}{c}= \\
\dot{n}\end{array}$ & $\begin{array}{l}\stackrel{2}{2} \\
\text { r }\end{array}$ \\
\hline
\end{tabular}

Fig. 5. Design diagrams of geometrical parameters of composite brake pad in AutoCAD with the upper wear of 12 $\mathrm{mm}$ and different clearances between the pad and the wheel from 4 to $9 \mathrm{~mm}$

Table 1. Dependence of the wear length of the composite block on its horizontal wear and the clearance between the wheel and the pad

Comparison of the data obtained in AutoCAD and Mathcad for 4 to $9 \mathrm{~mm}$ clearances between the pad and the wheel in numerical (Fig. 6, a) and percentage (Fig. 6, b) values, with the $12 \mathrm{~mm}$ abrasion of the top.

\subsection{Determination of the area of uneven pad wear}

Let us consider the calculation diagram for determining the wear area of the brake pad of a freight car (Fig. 7). 


$$
\begin{aligned}
& -\int_{x_{A^{\prime}}}^{x_{B}}\left(\sqrt{R^{2}-\left(x-x_{C}\right)^{2}}+z_{C}\right) d x+ \\
& +\int_{x_{C^{-}-R}}^{x_{A^{\prime}}}\left(\sqrt{R^{2}-\left(x-x_{C}\right)^{2}}+z_{C}\right) d x .
\end{aligned}
$$

According to the results of the conducted studies, the graphical dependences of the harmful volume $(V)$ of the pad wear (Fig. 8) on the magnitudes of the clearance between the pad and the wheel in case of the known horizontal wear at the top of the pad and the clearance between the pad and the wheel are shown.

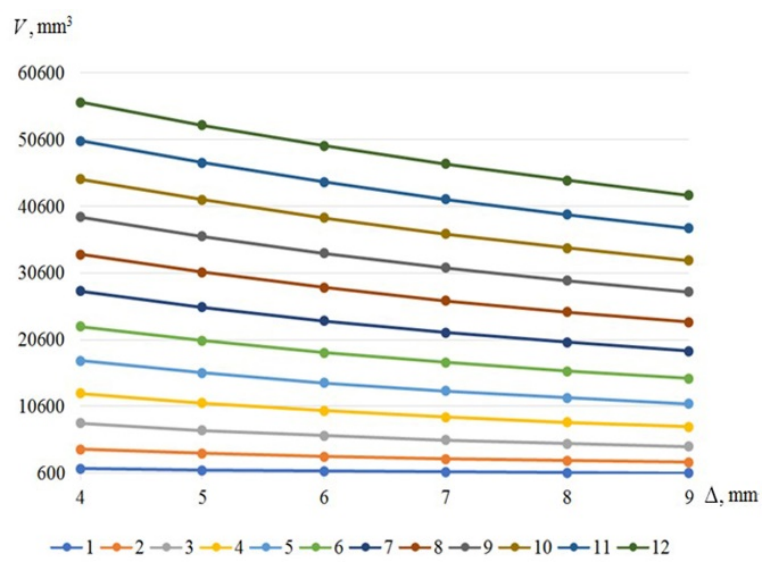

Fig. 6. Discrepancy between the results of AutoCAD and Mathcad: $\mathrm{a}$ - numerical values; $\mathrm{b}$ - percentage values.

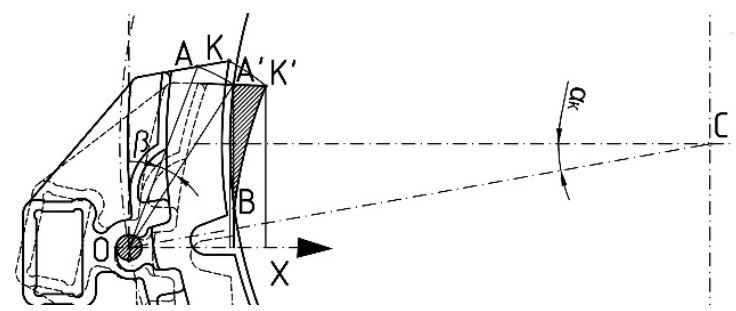

Fig. 7. Diagram for determining the area of uneven wear of the brake pad.

The area of the uneven wear of the brake pad can be defined as the area of the curvilinear trapezoid $Q=\int_{a}^{b} f(x) d x$, which requires composing an equation of the right line which goes through points $A^{\prime}, K^{\prime}$

$$
\frac{x-x_{A^{\prime}}}{x_{K^{\prime}}-x_{A^{\prime}}}=\frac{z-z_{A^{\prime}}}{z_{K^{\prime}} z_{A^{\prime}}} \text {, or } z=\frac{\left(x-x_{A^{\prime}}\right)\left(z_{K^{\prime}}-z_{A^{\prime}}\right)}{x_{K^{\prime}}-x_{A^{\prime}}}+z_{A^{\prime}} \text {. }
$$

The circle that simulates a car wheel

$$
\left(z-z_{C}\right)^{2}+\left(x-x_{C}\right)^{2}=R^{2}, \quad z=\sqrt{R^{2}-\left(x-x_{C}\right)^{2}}+z_{C} .
$$

The circle that goes through points $B, K^{\prime}$ with the centre in point $D$ (Fig. 3)

$$
\begin{aligned}
& \left(z-z_{D}\right)^{2}+\left(x-x_{D}\right)^{2}=(R+\Delta)^{2}, \\
& z=\sqrt{(R+\Delta)^{2}-\left(x-x_{D}\right)^{2}}+z_{D} .
\end{aligned}
$$

Area of the uneven wear

$$
\begin{aligned}
& Q=\int_{x_{A^{\prime}}}^{x_{K^{\prime}}}\left(\frac{\left(x-x_{A^{\prime}}\right)\left(z_{K^{\prime}}-z_{A^{\prime}}\right)}{x_{K^{\prime}}-x_{A^{\prime}}}+z_{A^{\prime}}\right) d x- \\
& -\int_{x_{B}}^{x_{K^{\prime}}}\left(\sqrt{(R+\Delta)^{2}-\left(x-x_{D}\right)^{2}}+z_{D}\right) d x-
\end{aligned}
$$

Fig. 8. Dependence of the amount of harmful wear in case of the known horizontal wear of the top of the pad and the clearance between the wheel and the pad.

To solve the problem of eliminating abnormal wear of the brake pads of freight cars, a device was proposed (Fig. 9) [15]. In the design, the brake strut was changed to prevent the abnormal wear of the brake pads in the bogies of freight cars for the entire regulated service life.

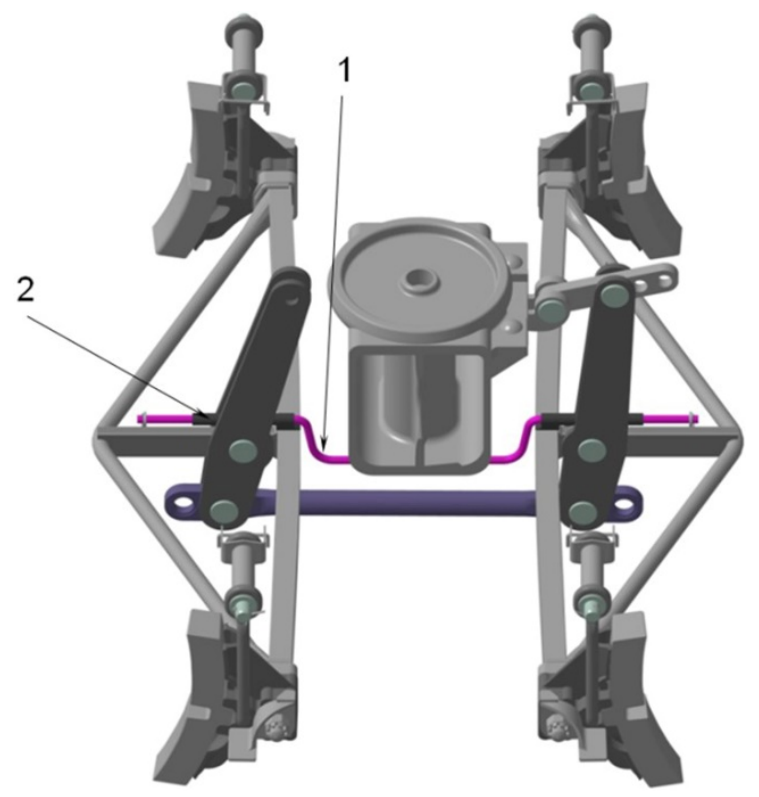

Fig. 9. General view of the device for standard retraction of the pads from the wheels in the brake system of freight cars: 1 - curved guide bar; 2 - cylindrical sliders 
This result is achieved when the triangle is balanced in the suspension axes and fixed when the brake is released and the pads are uniformly retracted without partial touching the wheels. The proposed device has two pairs of brake pads, which are rigidly fixed in the brake shoes on the centre shafts of triangles and are held near the rolling surface of the wheels on the pendulum suspension of the bogie; two-arm vertical levers that are hinged to the brake strut in which the joining hinge is located on the same straight line along the triangle pendulum suspension axis.

It consists of a curved guide bar, the ends of which are hinged in cylindrical sliders, rigidly attached along the adjacent brake struts symmetrically relative to the opening of the hinge that joins two-arm levers, while the downward cranked portions of the bar prevent the truck bolster of the car from resting on it in the loaded state and also prevent shifting and falling.

Introduction of distinctive features not only eliminates the negative effect of forces acting on the triangle when the brake is retracted from the mass of vertical levers, due to the location of the centre of the hinge that joins the vertical levers to the brake strut on the same line with the centres of the two support hinges of the brake shoes, at the same time, the curved guide bar will provide straightforward retraction of the brake pads from the wheels and hold them firmly parallel to the wheels when the brake is released, which generally simplifies the design of the device and provides more reliable operation in terms of uniform wear of brake pads.

\section{Conclusions}

On the basis of the conducted studies, the following conclusions can be drawn:

1. It is established that the wedge dual wear of the brake pads occurs due to the malfunction of the device for uniform retraction and retention of the brake pads relative to the moving surface of the counter body, which requires braking.

2. It is proved that the smaller the clearance between the pad and the wheel, and accordingly, the angle between the surface of the wheel rim and the working part of the pad is, the greater length of the brake pad from the top is worn when the brakes are released. However, it should be noted that with an excessive clearance, which is generally larger at the bottom of the pad than at top, intense wear at the upper edge of the pad occurs.

3. The principles of methodology for determining the geometrical parameters of brake pads of freight car are developed when the upper harmful attrition occurs, depending on the clearance between the pad and the wheel. Graphical dependences of the geometrical parameters of the pads were obtained according to the developed methodology, which in further works will allow estimating the braking efficiency of the freight train.

4. The results of calculations of the coordinate method performed in the Mathcad software environment and of the graphical one performed in AutoCAD to determine the geometrical parameters of the formation of the upper harmful wear of the pad depending on the standard clearance between the wheel and the brake pad were compared to proved theoretically that the error between them does not exceed 5-7\%.

\section{References}

1. Analysis of the state of train safety at the Ukrainian railways for 2017, Department of Car Facilities. (Fast Motion, Kiev, 2017)

2. A.A. Radzikhovsky, I.A. Omelyanenko, L.A. Timoshina, Brake pad retraction device. Wagon park 11/12, 18-21 (2008)

3. O.C. Ambikaprasad, A.R. Abhijeet, Failure Analysis of Brake Shoe in Indian Railway Wagon. IPASJ International Journal of Mechanical Engineering 3, 37-41 (2015)

4. R.C. Sharma, M. Dhingra, R.K. Pathak, Braking systems in railway vehicles. International Journal of Engineering Research \& Technology 4, 206-211 (2015)

5. V. Gupta, K. Saini, A.K. Garg, G. Krishan, O. Parkash, Comparative Analysis of Disc Brake Model for Different Materials Investigated Under Tragic Situations. Asian Review of Mechanical Engineering 5(1), 18-23 (2016)

6. S. Sarip, Design Development of Lightweight Disc Brake for Regenerative Braking - Finite Element Analysis. International Journal of Applied Physics and Mathematics 3(1), 52-58 (2013)

7. Y. Zhang, M. Zhang, The application status of unit brakes on metro vehicles in China. IOSR Journal of Mechanical and Civil Engineering 3(15), 17-23 (2018)

8. G. Vrtanoski, T. Smileski, Dynamic testing of innovative railway brake system for freight wagons. ANNALS of Faculty Engineering Hunedoara International Journal of Engineering 17, 83-89 (2019)

9. Operation Manual for Rolling Stock Brakes at the Ukrainian railways. CT-CB-CL-0015 (Polygraphservice, Kyiv, 2004)

10. A.N. Koptovets, L.N. Shirin, E.M. Shlyakhov, A.V. Denishchenko, V.V. Zil, V.V. Yavorskaya, Simulation of friction processes in the operation of pad wheel brake of underground locomotives (State Higher Educational Institution "National Mining University", Dnipro, 2017), p. 258

11. O. Fomin, A. Lovska, V. Pistek, P. Kucera, Dynamic load effect on the transportation safety of tank containers as part of combined trains on railway ferries. Vibroengineering procedia 29, 124 129 (2019)

12. S.I. Nechvolod, M.O. Romanyukha, K.S. Nechvolod, Problems of uneven wear of brake pads in freight cars. Proceedings 86, 50-56 (2007) 
13. J. Bird, Engineering Mathematics. Pocket reference book (Dodeka-XXI Publishing House, Moscow, 2008), p. 544

14. D.V. Kiryanov, Mathcad 13 (BHV-Petersburg, Saint Petersburg, 2006)

15. V.G. Ravlyuk, S.I. Nechvolod, Solution of the problem of wear of brake pads in bogies of freight cars. Bulletin of the East Ukrainian National University named after Vladimir Dahl 86, 140-143 (2017) 